\title{
Arazi Toplulaştırma Projelerinin Tarımsal Mekanizasyon İşletmeciliğine Etkisi
}

\section{Hamza KUZU ${ }^{\mathscr{2}}$, Hasan DEĞİRMENCİ2}

Kahramanmaraş Sütçü İmam Üniversitesi, Ziraat Fakültesi, Biyosistem Mühendisliği Bölümü, Kahramanmaraş ${ }^{1}$ https://orcid.org/0000-0001-8585-4467 ${ }^{2}$ https://orcid.org/0000-0002-6157-816X

凶: hamzakuzu@ksu.edu.tr

\section{ÖZET}

$\mathrm{Bu}$ araştırma; arazi toplulaştırma projelerinin tarımsal mekanizasyon işletmeciliğine etkisini belirlemek amacıyla Niğde İli Misli Ovasında gerçekleştirilen Aşlama, Çarıklı, Çayırlı, Karaatlı Köyü arazi toplulaştırma (AT) projelerinde yürütülmüştür. Basit tesadüfi örnekleme yöntemine göre seçilen 96 işletmeye ait parsellerin AT öncesi ve sonrası Alan Yol Uzunluğu Uygunluğu (AYU), Alan Kuş Uçuşu Yol Uzunluğu Uygunluğu (KUYUU), yakıt tüketimi, parsel işleme süresi, parsel başı dönüş kaybı, yol zaman kaybı ve parsel sınır alan kaybı parametreleri hesaplanmıştır. Çalışmada NetCAD programı kullanılmıştır. Seçilen işletmelerde AT öncesine göre AYU ve KUYUU değerleri sırasıyla ortalama \%43 ve \%37 azalmıştır. Yol uzunlukları kısaldığından yakıt tüketimi ortalama \%50, toplam üretim süresi \%36 azalmıştır. AT sonrası parsel sınır alan kaybı ortalama \%38, parsel başı dönüş kaybı \%38, parsellere ulaşımda geçen süre \%50, parsel işleme süresi \%5 düşmüştür. İstatistiksel olarak AT öncesi ve sonrası farklar önemli bulunmuştur $(\mathrm{P}<0.05)$.

\section{Araştırma Makalesi}

\author{
Makale Tarihçesi \\ Geliş Tarihi : 23.09.2019 \\ Kabul Tarihi : 09.01.2020
}

Anahtar Kelimeler
Tarımsal mekanizasyon
işletmeciliği
Arazi toplulaştırması
Sınır alan kaybı
Zaman kaybı
Yakıt tüketimi

\section{The Effect of Land Consolidation Projects on Agricultural Mechanization Management}

\section{ABSTRACT}

This research was conducted to determine the effects of land consolidation (LC) projects on agricultural mechanization management. In this study, LC projects of Aşlama, Çarıklı, Çayırlı and Karaatlı Village in the Misli Plain in Niğde was taken as material. According to the simple random sampling, 96 managements were selected and the pre and post LC parameters of the eligibility of area road length (AYU), the eligibility of area airline road length (KUYUU), the fuel consumption, the parcel processing time, the loss of parcel return, the loss of road time and the loss of area from parcel boundaries were calculated with the help of NetCAD program. AYU and KUYUU values of selected managements have decreased by $43 \%$ and $37 \%$ on average, respectively. Due to reducing road lengths, the fuel consumption and the total production time have decreased by $50 \%$ and by $36 \%$, respectively. After the LC parcel boundary area losses, the end of parcel return time, the time to reach the parcels, and the parcel processing time have decreased by $38 \%, 38 \%, 50 \%$ and $5 \%$, respectively. Differences before and after LC were statistically significant $(\mathrm{P}<0.05)$.

\section{Research Article}

$\begin{array}{ll}\text { Article History } & \\ \text { Received } & : 23.09 .2019 \\ \text { Accepted } & : 09.01 .2020\end{array}$

Keywords
Agricultural mechanization
management
Land consolidation
Loss of border area
Time loss
Fuel consumption

To Cite : Kuzu H, Değirmenci H 2020. Arazi Toplulaştırma Projelerinin Tarımsal Mekanizasyon İşletmeciliğine Etkisi. KSÜ Tarım ve Doğa Derg 23 (3): 655-662. DOI: 10.18016/ksutarimdoga.vi.623467

\section{GIRIŞ}

Tarımsal üretim faaliyetlerinde güç kaynakları ve gelişmiş tarım makinelerinin kullanılması tarımsal mekanizasyon olarak tanımlanmaktadır. Tarımsal mekanizasyon ile girdi maliyetleri azaltılabilir, çalışma kolaylığ , zaman ve işgücü tasarrufu, verim ve kalite artışı sağlanabilir.
Ülkemiz tarım işletmelerinde toprak yetersizliği ve toprak mülkiyetindeki dengesiz dağılım, parsellerin küçük, parçalı, dağınık ve şekilsiz olması gibi sorunlar üretim sisteminde yatırım giderlerini, işgücü ve zaman gereksinimlerini artırmaktadır (Yağanoğlu ve ark., 2000).

İşletmecilik başarısını düşüren parçalanmış, dağınık ve şekilsiz işletme parsellerinin modern tarım 
işletmeciliğine uygun şekilde birleştirilip yeniden düzenlenmesi arazi toplulaştırma (AT) olarak adlandirılır (Anonim, 2015).

AT çalışmaları ile parseller mekanizasyona daha uygun olan kare ve dikdörtgen şekillere getirildiğinden ve parsellerin birleştirilmesiyle yol güzergahları kısaldığından üretim faaliyetleri sırasında oluşabilecek yakıt, zaman ve iş gücü kayıpları azalmaktadır.

Birçok araştırmacı AT projelerinin tarımsal işletmeciliğe etkisini farklı yönleriyle araştırmıştır. Kumbasaroğlu ve Dağdemir (2007), Erzurum'da 34 köyde 116 tarım işletmesini ortalama parsel büyüklüğüne göre 4 grupta incelemiş ve ortalama parsel büyüklüğu 30 dekardan fazla olan işletmelerin ekonomik açıdan daha başarılı olduğunu bildirmiştir. Çelebi (2010) Karaman'da yaptığı çalışmada, 1554 hektar alanda yapılan toplulaştırma ile yatırım maliyetlerinin \%44.6 azaldığını belirlemiştir. Oğuz ve Bayramoğlu (2004), yaptıkları çalışmada, arazi toplulaştırması ile yakıt tüketiminin ortalama $\% 12-15$, çalışma süresinin $\% 20$, tohum kullanımının $\% 21$ ve gübre kullanımının \%17 azaldığını bildirmişlerdir. Küsek (2014), Konya'da yaptığı çalışmada, toplulaştırma çalışmalarının işgücü giderlerini $\% 68.75$, sürüm giderlerini $\% 27.12$ ve ulaşım giderlerini \%4.13 oranında azaldığını bildirmiştir. Boztoprak (2010), Kayseri ilinde yaptığı çalışmasında toplulaştırma ile parsel sınır alan kayıplarının $\% 22.26$, toprak işleme süresinin $\% 72.52$, yol süresinin
$\% 44.80$, toplam hazırlanma süresinin $\% 30.49$ ve yol uzunluğunun $\% 56.24$ oranında düştüğünü belirtmiştir. Hung (2017), yaptığı çalışmada arazi toplulaştırmayla işletmelerin makine kullanma oranının \%75.8'den \%89.8'e yükseldiğini ve ortalama maliyetin \%10 düştüğünü, Harasimowicz ve ark. (2017) ise parsel sayısının \%39.14, parsellere olan uzaklığın \%32.76, parsellere ulaşım ve üretim maliyetlerinin \%38.62 oranında düştüğünü bildirmiştir. Kuşlu ve Ertem (2019), yaptıkları çalışmada arazi toplulaştırmayla işletme merkezi ile parseller arası yol uzunluğu ortalamasının \%7.14 dolayında azaldığını, yol ağının yaklaşık \%62.50 oranında iyileştiğini ve yoldan faydalanan parsel oranının \%68'den \%100'e ulaştığını belirlemişlerdir.

$\mathrm{Bu}$ çalışmanın amacı arazi toplulaştırma çalışmalarının tarımsal mekanizasyon işletmeciliğine olan etkisini; alan, zaman ve yakıt kaybı yönünden araştırmak ve işletmecilik açısından toplulaştırma öncesi ve sonrası durumu karşılaştırmaktır.

\section{MATERYAL ve METOT}

\section{Materyal}

Bu çalışmada Niğgde İli Misli Ovası merkeze bağlı Aşlama, Çarıklı, Çayırlı ve Karaatlı Köylerinde yürütülen arazi toplulaştırma proje verileri kullanılmıştır. Araştırma alanının konumu Şekil 1.'de ve arazi toplulaştırma öncesi (ATÖ) ve sonrasına (ATS) yönelik bilgiler Çizelge 1.'de verilmiştir.

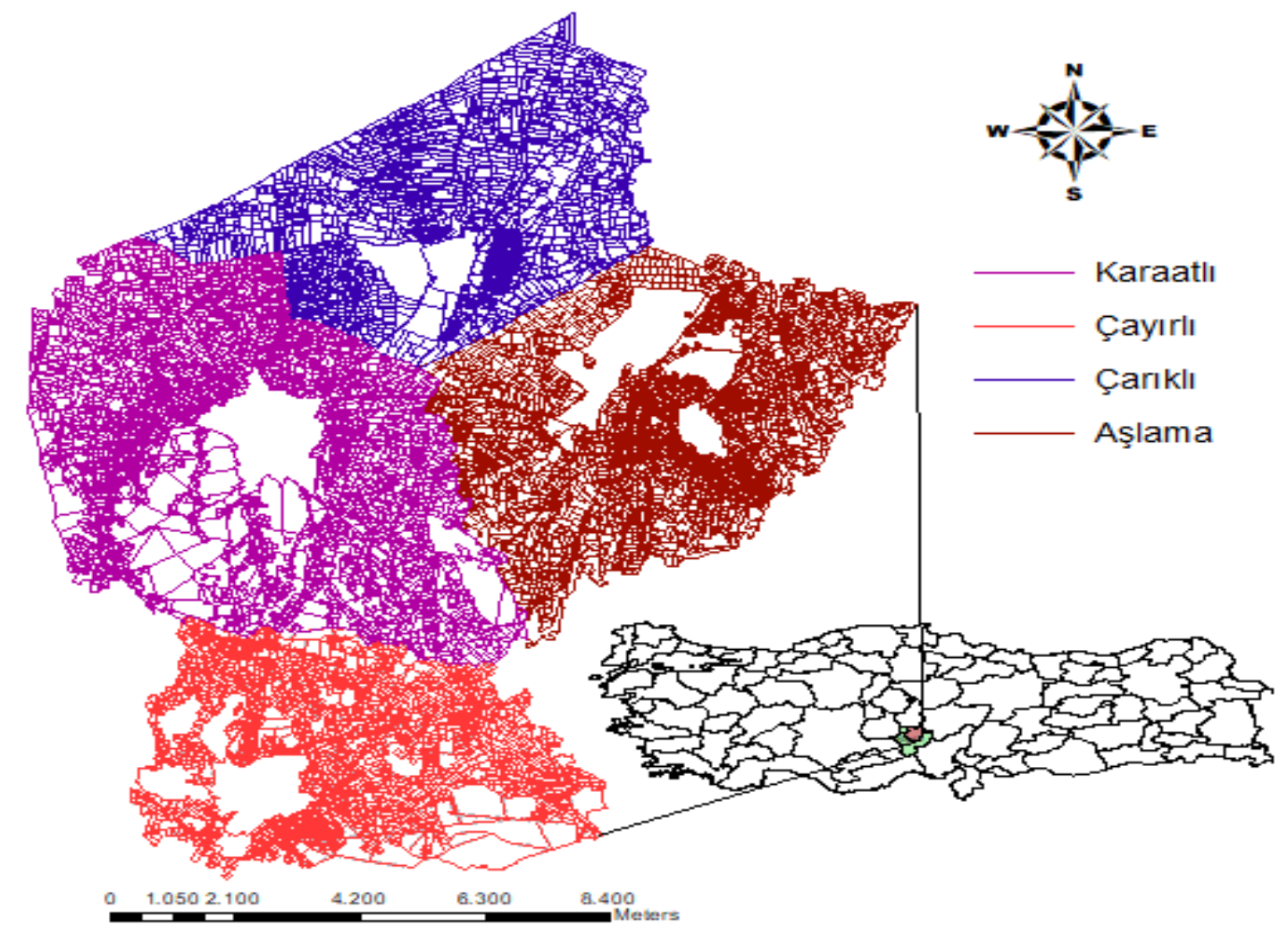

Şekil 1. Araştırma alanı konum haritası

Figure 1. Location map of the research area 
Çizelge 1. Çalışma alanına yönelik AT öncesi ve sonrası genel bilgiler

Table 1. General information about the study area before and after the $L C$

\begin{tabular}{|c|c|c|c|c|c|c|c|c|c|}
\hline \multirow{2}{*}{ Köyler } & \multicolumn{2}{|c|}{ Parsel Sayısı (Adet) } & \multicolumn{2}{|c|}{$\begin{array}{l}\text { Ortalama Parsel } \\
\text { Büyüklüğü (da) }\end{array}$} & \multicolumn{2}{|c|}{$\begin{array}{l}\text { Ortalama İşletme } \\
\text { Büyüklüğü (da) }\end{array}$} & \multirow{2}{*}{$\begin{array}{l}\text { Malik } \\
\text { Sayısı } \\
\text { (adet) }\end{array}$} & \multirow{2}{*}{$\begin{array}{l}\text { İşletme } \\
\text { Sayısı } \\
\text { (adet) }\end{array}$} & \multirow{2}{*}{ TO $(\%)$} \\
\hline & ATÖ & ATS & ATÖ & ATS & ATÖ & ATS & & & \\
\hline Aşlama & 4212 & 1930 & 8.90 & 19.02 & 38.72 & 37.92 & 8448 & 968 & 54.18 \\
\hline Çarıklı & 1993 & 1533 & 15.70 & 19.77 & 23.88 & 23.14 & 4893 & 1310 & 23.08 \\
\hline Çayırlı & 3119 & 2005 & 9.05 & 13.83 & 22.66 & 22.25 & 5260 & 1246 & 35.72 \\
\hline Karaatlı & 4501 & 2804 & 10.18 & 16.00 & 35.47 & 34.72 & 7955 & 1292 & 37.70 \\
\hline
\end{tabular}

TO: Toplulaştırma oranı, ATÖ: Arazi Toplulaştırma Öncesi, ATS: Arazi Toplulaştırma Sonrası

Metot

Örneklem seçimi

İşletme sayısının fazla olması nedeniyle basit tesadüfi örnekleme yöntemine göre (Newbold, 1995) \%10 hata ve \%95 güven aralığında Eşitlik 1'e göre 96 işletme seçilmiş ve seçilen örnek işletme sayıları Çizelge 2'de verilmiştir.

$$
n=\frac{N_{P}(1-p)}{(N-1) \sigma_{p x}^{2}+p(1-p)}
$$

$\mathrm{n}$ : Örnek işletme sayısı,

$\mathrm{N}$ : Popülasyondaki işletme sayısı,

$\sigma^{2}$ : Popülasyonu oluşturan işletmelerin varyansı,

$\mathrm{p}$ : Aranılan özelliğin rastlanma sıklığı (maksimum örnek için 0.5),

px: 1-p göstermektedir.

Çizelge 2. Seçilen örnek işletme sayıları

Table 2. Selected sample management numbers

\begin{tabular}{llllll}
\hline & Köyler & & & \\
\hline & Aşlama & Çarıklı & Çayırlı & Karaatlı & Toplam \\
İşletme sayısı & 968 & 1310 & 1246 & 1292 & 4816 \\
Örnek işletme sayısı & 19 & 26 & 25 & 26 & 96 \\
\hline
\end{tabular}

\section{Yakıt tüketimi}

Çalışma alanında en çok buğday üretimi yapıldığından, işletmenin bir üretim döneminde parsellerine ulaşımda tükettiği yakıt, buğday üretiminde yapılan faaliyetlere göre hesaplanmıştır. İşletmelerin $\mathrm{km}$ başına ortalama 0.407 litre yakıt harcadığı kabul edilmiştir (Polat ve Manavbaşı, 2012).

\section{Parsel sinir alan kaybı}

Parsel sinırı boyunca 0.30 m'nin tam olarak kullanılamadığı kabul edilmiştir (Çevik, 1974). Bu kayıp alan, parselin çevre uzunluğu büyüdükçe artmaktadır.

\section{Alan-yol uzunluğu uygunluğu (AYU)}

Bu gösterge değerinin 1'e yaklaşması işletme için daha iyi bir yol işletim sistemini ifade etmektedir (Platonova ve ark., 2011). Formül Eşitlik 2'de verilmiştir.

$$
A Y U=\frac{Y U}{0.043 \sqrt{P A}}
$$

Eşitlikte;

AYU: Alan-yol uzunluğu uygunluğu

PA : Parsel alanı (ha)

YU : İşletme merkezi ile parsel arası yol uzunluğu $(\mathrm{km})$
Alan-kuş uçuşu yol uzunluğu uygunluğu (KUYUU)

$\mathrm{Bu}$ gösterge değeri 1'e yaklaştıkça yol işletim uygunluğu artmaktadır (Platonova ve ark., 2011). Formül Eşitlik 3’te verilmiştir.

$$
K U Y U U=\frac{K U Y U}{0.038 \sqrt{P A}}
$$

Eşitlikte;

KUYUU: Alan-kuş uçuşu yol uzunluğu uygunluğu

PA : Parsel alanı (ha)

KUYU : İşletme merkezi ile parsel arası kuş uçuşu yol uzunluğu $(\mathrm{km})$

\section{Yol zaman kaybı}

İşletmelerin parsellerine ulaşımda geçirdikleri zaman hesaplanırken gidiş dönüşte ortalama hızlarının 15 $\mathrm{km} \mathrm{h}^{-1}$ olduğu kabul edilmiştir (Boztoprak ve ark., 2015).

\section{Parsel başı dönüşlerinde zaman kaybı}

Parsel başı dönüşlerinde harcanan zaman, parsel enine ve kullanılan tarım alet ekipmanlarına bağlı olup, parsel genişliği arttıkça kayıp artmaktadır (Ayrancı, 2004). Formül Eşitlik 4'te verilmiştir.

$$
Y D=\frac{100 a B}{60 b}
$$

Eşitlikte;

YD: Parsel başı dönüşlerinde zaman kaybı (h) 
a : Parsel başlarında bir dönüş için geçen ortalama zaman (dak)

B : Parsel genişliği (m)

b : Kullanılan aracın efektif iş genişliği (cm)

\section{Parsel işleme süresi}

Parsel işleme süresi; parsel büyüklüğüne, makine iş genişliğine ve makine ortalama hızına göre değişmektedir (Dinçer, 1970). Formül Eşitlik 5'te verilmiştir.
$T e=\frac{B L}{10 b V}$

Eşitlikte;

Te: Parsel işleme süresi (h)

B : Parsel genişliği (m)

L : Parsel uzunluğu (m)

b : Kullanılan aracın efektif iş genişliği $(\mathrm{cm})$

$\mathrm{V}$ : Kullanılan aracın ortalama çalışma hızı $\left(\mathrm{km} \mathrm{h}^{-1}\right)$

Buğday tarımında yapılan faaliyetler için parsel başlarında geçen ortalama zaman, makine iş genişliği ve ortalama çalışma hızı Çizelge 3’te verilmiştir (Ayrancı, 2004; Say, 2001).

Çizelge 3. Buğday üretiminde gerçekleştirilen faaliyetlerin sayısı, parsel başında geçen ortalama zaman, makine iş genişliği ve ortalama çalışma hızı

Table 3. Number of operations, average passing time beginning of parcel, machine working width and average working speed in wheat production

\begin{tabular}{l|llcc}
\hline Faaliyet & $\mathrm{a}$ & $\mathrm{b}$ & Sayısı & $\begin{array}{c}\text { Ortalama çalışma hızı } \\
\left(\mathrm{km} \mathrm{h}^{-1}\right)\end{array}$ \\
\hline 1.Sürüm & 0.30 & 91 & 1 & 7 \\
2.Sürüm & 0.30 & 350 & 1 & 10 \\
3.Sürüm & 0.30 & 300 & 1 & 9 \\
Ekim & 0.30 & 250 & 1 & 8 \\
Gübreleme & 0.30 & 600 & 3 & 8 \\
İlaçlama & 0.30 & 460 & 1 & 8 \\
Balyalama & 0.30 & 160 & 1 & 6 \\
Hasat & 0.35 & 457 & 1 & 5 \\
\hline
\end{tabular}

a; dönme zamanı (dak), b; tarım makinesi iş genişliği $(\mathrm{cm})$

Buğday tarımında tarla etkinliği kare ve dikdörtgende 0.94, yamuk ve üçgende 0.90 ve şekilsiz parsellerde 0.85 alınmıştır (Say, 2001). Parsel başı dönüşler ve parsel işleme süreleri bu sebeple etkinlik değerlerine bölünerek efektif sonuçlara dönüştürülmüştür. Gerçekleştirilen tarımsal faaliyete göre kabul edilen ortalama çalışma hızları, Kepner ve ark. (1980); Hunt (1983) ve ASAE (1994) çalışmalarından alınmıştır (Sabancı ve ark., 2010).

\section{İstatistiksel değerlendirme}

Seçilen işletmeler için AT öncesi ve sonrası hesaplanan gösterge ortalamaları arasındaki farkın istatistiksel olarak önemli olup olmadığını belirlemek için t testi (paired-sample t-test) yapılmıştır.

\section{BULGULAR ve TARTIŞMA}

Hesaplanan AYU, KUYUU, yakıt tüketimi ve sınır alan kaybı göstergelerinin minimum, maksimum, ortalama ve standart sapma değerleri Çizelge 4'de verilmiştir. AT ile ortalama AYU değeri Aşlama'da $\% 42$, Çarıklı'da \%44, Çayırlı'da \%36 ve Karaatlı'da $\% 49$, ortalama KUYUU değeri ise sirasiyla \%38, \%32, $\% 33$ ve \%47 oranında düşmüştür. 4 köyde de AYU ve KUYUU AT öncesi ve sonrası ortalama değerleri arasındaki fark istatistiksel olarak önemlidir $(\mathrm{P}<0.05)$. Değirmenci ve ark. (2017), benzer sonuçlar bulmuş ve AYU ile KUYUU arasında pozitif bir ilişki olduğunu ifade etmişlerdir. Platonova ve ark. (2011), AYU ve KUYUU değerinin 1 olmasının işletme yol uygunluğu için en iyi değer olacağını belirtmiştir. Araştırma alanında AT ile işletmelerin daha iyi bir işletim uygunluğu kazandığı, mevcut yol ağı sisteminin kalitesinin arttığ ve yolların daha az dönemeçli hale geldiği ifade edilebilir. Ayrıca seçilen işletme parsellerinin tamamı yola cephe kazanmıştır. Şekil 2'de örnek bir işletmenin AT öncesi ve sonrası yola cephe durumu gösterilmiştir.

İşletmelerin yakıt tüketim ortalamaları AT ile Aşlama'da \%51, Çarıklı'da \%52, Çayırlı'da \%51 ve Karaatlı'da \%47 oranında azalmıştır. AT öncesi ve sonrası yakıt tüketiminde önemli bir fark vardır. Bu fark 4 köy için de istatistiksel olarak önemlidir $(\mathrm{P}<0.05)$. Kuzu ve ark. (2018) toplulaştırma sayesinde yol uzunlukları düştüğü için ortalama yakıt tüketiminde yaklaşık \%16 tasarruf edildiğini, Polat ve Manavbaşı (2012) ise yol güzergahlarının ortalama $26.68 \mathrm{~km}$ kısalmasıyla yakıt tüketimlerinin ortalama 10.86 litre azaldığını bildirmiştir. Ayten ve Çay (2017), örnek bir işletmenin parsellerine gidiş gelişte harcadığ litreye düştüğünü ifade etmiştir.

Parsel sinır alan kaybı ortalamaları, AT ile birlikte Aşlama'da \%40, Çarıklı 'da \%34, Çayırlı'da \%38 ve Karaatlı'da \%40 azalmıştır. İşletmelerin parsel sınır alan kayıpları değerleri arasındaki AT öncesi ve sonrası fark 4 köy için de istatistiksel olarak önemlidir 
( $\mathrm{P}<0.05)$. Çevik (1974), yaptığı çalışmada parsel sayısı 5, alanı 34 dekar olan bir işletmenin toplulaştırma

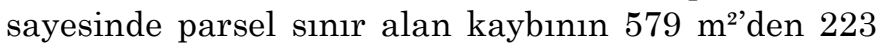
m²'ye düştüğünü (Arıcı ve Akkaya Aslan, 2014),
Boztoprak ve ark. (2015) ise AT projesi kapsamındaki işletmelerde toplam sınır alan kaybının toplulaştırma sayesinde 233 dekardan 181 dekara düştüğünü ve azalma oranının \%22 olduğunu belirtmiştir.

Çizelge 4. AT öncesi ve sonrası AYU, KUYUU, yakıt tüketimi ve sınır alan kaybı değerleri

Table 4. AYU, KUYUU, fuel consumption and loss of boundary values before and after LC

\begin{tabular}{|c|c|c|c|c|c|c|c|c|c|}
\hline \multirow[t]{2}{*}{ Köyler } & \multirow[t]{2}{*}{ Değer } & \multicolumn{2}{|l|}{ AYU } & \multicolumn{2}{|c|}{ KUYUU } & \multicolumn{2}{|c|}{ Yakıt tüketimi (L) } & \multicolumn{2}{|c|}{ Sinır alan kaybı $\left(\mathrm{m}^{2}\right)$} \\
\hline & & ATÖ & ATS & ATÖ & ATS & ATÖ & ATS & ATÖ & ATS \\
\hline \multirow{4}{*}{ 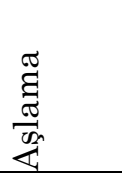 } & $\min$. & 32.55 & 10.93 & 30.84 & 12.23 & 19.77 & 6.59 & 92.92 & 62.89 \\
\hline & $\max$. & 190.86 & 157.43 & 194.71 & 157.01 & 483.91 & 178.85 & 808.34 & 538.82 \\
\hline & ort. & 96.87 & 56.11 & 90.68 & 56.45 & 120.41 & 58.59 & 309.25 & 185.29 \\
\hline & sdt. & 50.75 & 40.16 & 46.47 & 40.27 & 108.61 & 49.72 & 217.79 & 119.41 \\
\hline \multirow{4}{*}{$\begin{array}{l}\vec{y} \\
\vec{z} \\
\vec{z}\end{array}$} & $\min$. & 41.28 & 23.08 & 34.01 & 21.94 & 25.10 & 18.99 & 79.19 & 81.49 \\
\hline & $\max$. & 227.47 & 134.22 & 177.55 & 111.69 & 225.64 & 117.03 & 843.77 & 560.87 \\
\hline & ort. & 121.34 & 68.00 & 91.88 & 62.80 & 117.78 & 56.26 & 269.96 & 178.79 \\
\hline & sdt. & 48.20 & 30.97 & 36.88 & 27.30 & 58.97 & 20.19 & 170.34 & 109.46 \\
\hline \multirow{4}{*}{ 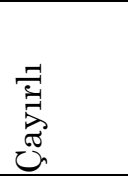 } & $\min$. & 37.86 & 19.70 & 38.16 & 21.32 & 16.47 & 14.38 & 87.47 & 66.47 \\
\hline & $\max$. & 231.56 & 148.49 & 238.25 & 148.11 & 388.56 & 177.64 & 884.54 & 464.06 \\
\hline & ort. & 99.08 & 63.62 & 96.03 & 64.31 & 111.29 & 54.90 & 259.58 & 160.84 \\
\hline & sdt. & 52.47 & 32.97 & 53.37 & 33.64 & 97.62 & 37.15 & 209.63 & 102.60 \\
\hline \multirow{4}{*}{ 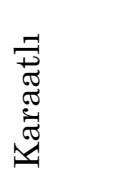 } & $\min$. & 43.61 & 28.58 & 49.21 & 27.80 & 21.62 & 21.39 & 103.04 & 67.22 \\
\hline & $\max$. & 253.12 & 147.81 & 254.76 & 134.88 & 281.43 & 155.20 & 858.32 & 366.09 \\
\hline & ort. & 116.43 & 59.18 & 113.72 & 60.10 & 108.06 & 56.86 & 303.12 & 182.35 \\
\hline & sdt. & 50.92 & 27.96 & 48.68 & 27.25 & 67.79 & 30.82 & 188.31 & 86.19 \\
\hline
\end{tabular}

ATÖ: Arazi Toplulaştırma Öncesi, ATS: Arazi Toplulaştırma Sonrası
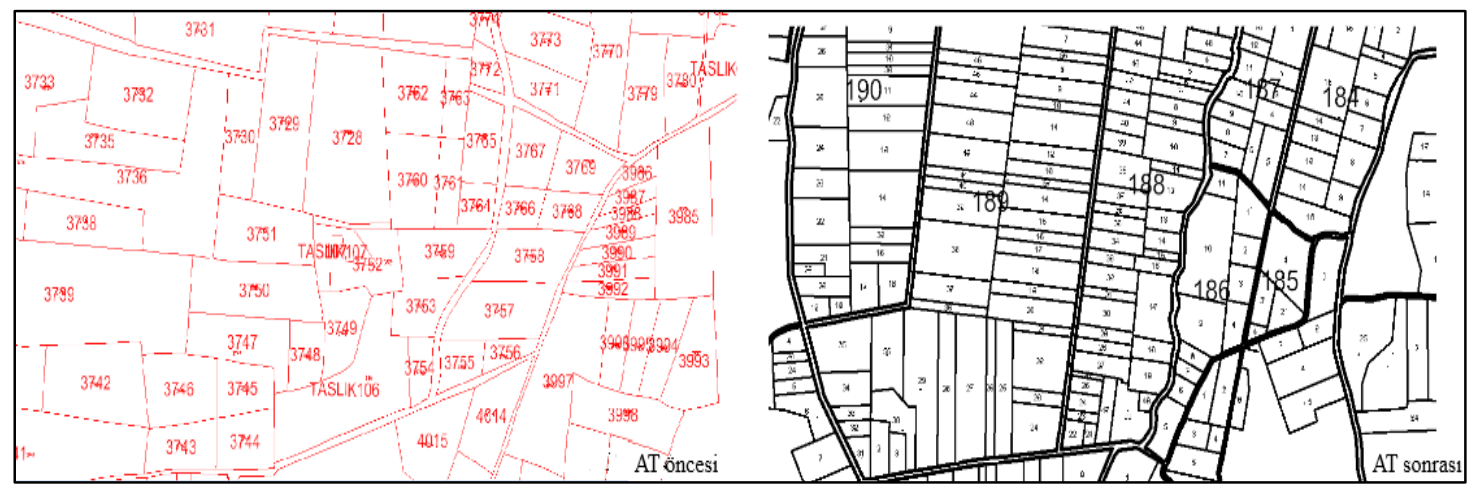

Şekil 2. Parsellerin AT öncesi ve sonrası yola cephe durumu

Figure 2. The front position of the parcels to road before and after LC

İşletmelerin bir üretim döneminde harcadıkları zaman, işletme merkezinden parsellerine giderken yolda harcanan zaman, parsel içi tarımsal faaliyetlerde harcanan zaman ve parsel başı dönüşlerde kaybedilen zamanın toplamıdır. Hesaplanan zaman kaybı göstergelerinin minimum, maksimum, ortalama ve standart sapma değerleri Çizelge 5'de verilmiştir.

İşletmenin parsellerine uzaklığına bağlı olarak parsellere ulaşım için geçen zaman farklı değerler almıştır. Tarımsal faaliyetler için harcanan zaman parsel alanına göre değişiklik göstermiştir. Parsel şeklinin kare, dikdörtgen gibi düzgün şekilli veya şekilsiz olması faaliyet süresini etkilemektedir.
Seçilen işletmelerin parsellerine gidiş dönüşte geçen ortalama toplam zaman AT ile yaklaşık olarak, Aşlama'da 20'den 10'a, Çarıklı'da 19'dan 9'a, Çayırlı'da 18'den 10'a ve Karaatlida 18 saatten 9 saate düşmüştür. Ayten ve Çay (2017), örnek bir işletmenin benzer şekilde parsellerine gidiş dönüşte yıllık yaklaşık 35 saat harcarken AT ile artık 6 saat harcadığını bildirmiştir.

AT ile parsel başı dönüşlerinde ortalama zaman kaybı yaklaşık olarak, Aşlama'da 3.17'den 1.99 saate, Çarıklı'da 2.34'ten 1.51'e, Çayırlı'da 2.5'ten 1.63'e, Karaatlı'da 3.02'den 1.66'ya düşmüştür. Parsel eni arttıkça parsel başlarındaki dönüş sayısı ve buna bağlı olarak da zaman kaybı artmaktadır. Ayrancı (2004), yaptığı çalışmada mısır tarımında yıllık parsel başı 
dönüş kayıplarının boy/en oranı 0.5 olan parselde 1.27 saat iken boy/en oranı 1, 2, 3, 4 ve 5 olan parseller için sirasiyla $0.92,0.63,0.53,0.45$ ve 0.41 saat olduğunu belirtmiştir.

Parsel işleme süresi ortalaması AT öncesi Aşlama'da 11.01, Çarıklı'da 7.55, Çayırlı'da 6.99, Karaatlı'da 8.64 saat iken AT sonrası Aşlama'da 10.33, Çarıklı'da 7.16, Çayırlı'da 6.67 ve Karaatlı'da 8.42 saat olmuştur. Parsel işleme süresi AT öncesi ve sonrası değerlerinde Karaatlı'da istatistiksel olarak fark bulunmazken
( $\mathrm{P}>0.05)$; Aşlama, Çarıklı ve Çayırlı'da istatistiksel olarak fark bulunmaktadır $(\mathrm{P}<0.05)$. Parsel işleme süresi parsel alanına bağlı olarak artmaktadır. Parsel alanları eşit olan parsellerde işleme süresi parsel şekilsizleştikçe artar, en uygun parsel şekli dikdörtgendir (Boyacıoğlu, 1975).

Toplam üretim süresi ise AT ile yaklaşık olarak, Aşlama'da 33.90 saatten 21.92 saate, Çarıklı'da 29.18'den 17.89'a, Çayırlı'da 27.72'den 17.29'a ve Karaatlı'da 29.37'den 19.39'a düşmüştür.

Çizelge 5. AT öncesi ve sonrası zaman kayıpları temel istatistik değerleri

Table 5. Basic statistical values of time losses before and after $L C$

\begin{tabular}{|c|c|c|c|c|c|c|c|c|c|}
\hline \multirow[t]{2}{*}{ Köyler } & \multirow[t]{2}{*}{ Değer } & \multicolumn{2}{|c|}{$\underset{(\mathrm{h})}{\text { Yol Zaman Kaybı }}$} & \multicolumn{2}{|c|}{$\begin{array}{c}\text { Parsel Dönüş Kaybı } \\
(\mathrm{h})\end{array}$} & \multicolumn{2}{|c|}{$\begin{array}{c}\text { Parsel İşleme Süresi } \\
\text { (h) }\end{array}$} & \multicolumn{2}{|c|}{$\begin{array}{l}\text { Toplam üretim İcin } \\
\text { Geçen Süre (h) }\end{array}$} \\
\hline & & ATÖ & ATS & ATÖ & ATS & ATÖ & ATS & ATÖ & ATS \\
\hline \multirow{4}{*}{ 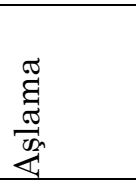 } & $\min$. & 3.24 & 1.08 & 0.60 & 0.57 & 1.37 & 1.24 & 7.05 & 3.96 \\
\hline & $\max$. & 79.26 & 29.29 & 8.95 & 6.18 & 46.77 & 44.44 & 112.82 & 79.92 \\
\hline & ort. & 19.72 & 9.60 & 3.17 & 1.99 & 11.01 & 10.33 & 33.90 & 21.92 \\
\hline & sdt. & 17.79 & 8.14 & 2.34 & 1.56 & 12.14 & 11.38 & 29.83 & 20.00 \\
\hline \multirow{5}{*}{ 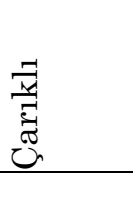 } & min. & 4.11 & 3.11 & 0.16 & 0.16 & 1.73 & 1.68 & 7.21 & 5.85 \\
\hline & $\max$. & 36.96 & 19.17 & 8.88 & 4.73 & 25.19 & 24.46 & 71.03 & 48.36 \\
\hline & ort. & 19.29 & 9.22 & 2.34 & 1.51 & 7.55 & 7.16 & 29.18 & 17.89 \\
\hline & sdt. & 9.66 & 3.31 & 1.91 & 1.20 & 6.78 & 6.47 & 15.51 & 9.73 \\
\hline & $\min$. & 2.70 & 2.36 & 0.74 & 0.45 & 1.44 & 1.38 & 5.83 & 5.62 \\
\hline \multirow{3}{*}{ 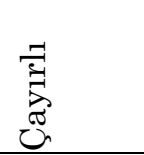 } & $\max$. & 63.65 & 29.10 & 7.55 & 5.40 & 30.71 & 29.17 & 92.32 & 52.13 \\
\hline & ort. & 18.23 & 8.99 & 2.50 & 1.63 & 6.99 & 6.67 & 27.72 & 17.29 \\
\hline & sdt. & 15.99 & 6.09 & 1.85 & 1.26 & 7.62 & 7.13 & 23.58 & 13.24 \\
\hline \multirow{4}{*}{ 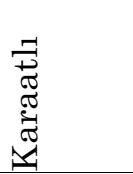 } & $\min$. & 3.54 & 3.50 & 0.71 & 0.39 & 1.50 & 1.45 & 6.23 & 5.86 \\
\hline & max. & 46.10 & 25.42 & 7.63 & 3.81 & 27.76 & 25.82 & 54.82 & 43.35 \\
\hline & ort. & 17.70 & 9.31 & 3.02 & 1.66 & 8.64 & 8.42 & 29.37 & 19.39 \\
\hline & sdt. & 11.10 & 5.05 & 1.95 & 0.99 & 7.47 & 7.35 & 16.18 & 11.66 \\
\hline
\end{tabular}

ATÖ: Arazi Toplulaştırma Öncesi, ATS: Arazi Toplulaştırma Sonrası

\section{SONUÇ ve ÖNERILER}

Aşlama, Çarıklı, Çayırlı ve Karaatlı Köylerinde yürütülen arazi toplulaştırma projeleri ile parsel sayıları düşmüştür. Toplulaştırma oranları yüksek olmamasına rağmen parsel şekilleri daha düzgün hale gelmiştir. Böylece parseller işletmecilik açısından mekanizasyon için daha uygun hale geldiğinden işlenmesi kolaylaşmıştır. Ayrıca parsel sınır uzunlukları şekilsiz parsellerde arttığı için şekilsiz parsellerin azalması ile sınır alan kayıpları azalmıştır. Seçilen işletmelerde AT ile sınır alan kayıpları azalmıştır. Buna göre işletme parsellerinde kullanılabilir alan artacağından dolayı üretim miktarı ve işletme geliri de artabilir.

Yol işletim uygunluğunu ifade eden AYU ve KUYUU göstergeleri azalarak en uygun değer olan 1'e yaklaşmıştır. Yol ağı sisteminin iyileştirilmesiyle işletmelerin parsellerine ulaşımı kolaylaşmış ve işletme giderlerinde önemli bir yer tutan yakıt tüketimi de düşmüştür.
İşletmeler için zaman çok önemli olduğundan yaşanacak zaman kayıpları işletmeler için önemli gelir kayıplarına yol açabilir. Seçilen işletmelerde toplulaştırma sayesinde bir üretim dönemi boyunca üretim için geçen toplam zaman azalmıştır.

Ayrıca tüm parsellerin yola cepheli hale gelmesi ile sınır ihlallerinden kaynaklanan işletmeler arasındaki huzursuzluklar azalabilir. Yakıt tüketiminin düşmesi ile yakıt giderlerinin azalmasının yanında çevreye zararlı emisyonlar da azalabilir.

Hesaplanan göstergeler ışı̆̆ında işletmelerin önemli kazanımlar elde ettiğini ve arazi toplulaştırma projelerinin bu yönüyle ülkemiz için çok önemli olduğunu ve bu projelerin artırılması gerektiğini söyleyebiliriz.

Arazi toplulaştırma projelerinin tarımsal işletmelere etkilerinin değerlendirilmesinde göstergelerin birlikte kullanılması daha sağlıklı sonuçlar verecektir. 


\section{TEŞEKKÜR}

Bu makale Hamza Kuzu'nun yüksek lisans tezinden yararlanarak hazırlanmıştır.

\section{Çıkar Çatışması Beyanı}

Makale yazarları aralarında herhangi bir çıkar çatışması olmadığını beyan ederler.

\section{Araştırmacıların Katkı Oranı Beyan Özeti}

Yazarlar makaleye eşit oranda katkı sağlamış olduklarını beyan ederler.

\section{KAYNAKLAR}

Anonim 2015. Arazi Toplulaştırması. https://ankara.tarimorman.gov.tr/Belgeler/liftet/ar azitoplulastirmasi.pdf .

Arıcı I, Akkaya Aslan ŞT 2014. Arazi Toplulaştırması Planlama ve Projelemesi. Dora Yayınları, Bursa, $237 \mathrm{~s}$.

ASAE 1994. ASAE Standards-Uniform Terminology for Agricultural Machinery Management, ASAE S322.1. American Society of Agricultural Engineers. St. Joseph, MI. 49085-9659.

Ayranc1 Y 2004. Bir Parselde Optimum Boy/En Oranının Belirlenmesinde Bir Yaklaşım. Selçuk Tarım Bilimleri Dergisi, 18(33), 1-7.

Ayten T, Çay T 2017. Effects of the Purpose Expropriation of Land Consolidation to Landholding. World Academy of Science, Engineering and Technology, International Science Index 121, International Journal of Environmental, Chemical, Ecological, Geological and Geophysical Engineering, 11(1), 79- 82.

Boyacıŏlu R 1975. Arazi Toplulaştırılması Yapılan Erzincan Güllüce Köyündeki Tarımsal İşletmelerin Ekonomik Analizi. Topraksu Teknik Dergisi, Sayı:57, Ankara, 131s.

Boztoprak T 2010. Arazi Toplulaştırma Çalışmasının Kültürteknik Özelliklerinin Sürdürülebilir Arazi Yönetimi Açısından İrdelenmesi: Kayseri Örneği, Karadeniz Teknik Üniversitesi Fen Bilimleri Enstitüsü Harita Mühendisliği Anabilim Dalı, Yüksek Lisans Tezi.

Boztoprak T, Demir O, Çoruhlu YE, Nişancı R 2015. Arazi Toplulaştırmasının Tarımsal İşletmelere Etkilerinin Araştırılması. Selcuk University Journal of Engineering, Science And Technology, $3(3), 1-11$.

Çelebi M 2010. Toplulaştırmanın Karaman İlinde Sulama ve Diğer Tarımsal Faaliyetlerin Verimliliği Üzerinde Etkileri. Tarım Bilimleri Araştırma Dergisi, 3 (2): 1-6.

Çevik B 1974. Konya İli Çumra-Karkın Köyünün Kültürteknik Sorunları ve $\mathrm{Bu}$ Sorunların Çözümünde Arazi Toplulaştırmasının Yeri ve Önemi Üzerine Bir Araştırma. Ç.Ü. Ziraat
Fakültesi Yayınları No:52, A.Ü. Basımevi, (Doktora Tezi), 102s., Ankara.

Değirmenci H, Arslan F, Tonçer R, Yoğun E 2017. Arazi Toplulaştırma Öncesi Parsel Şekilleri ve Arazi Parçalanmasının Değerlendirilmesi Niğde Misli Ovası Tırhan Köyü Örneği. Gaziosmanpaşa Üniversitesi Ziraat Fakültesi Dergisi, 34(3):182189.

Dinçer H 1970. Tarla Alet ve Makinalarının İ Başarıları Hesaplanmasında Pratik Metot. Atatürk Üniversitesi Ziraat Fakültesi Dergisi- Journal of the Faculty of Agriculture 1(2): 49-62.

Harasimowicz S, Janus J, Bacior S, Gniadek J 2017. Shape and Size of Parcels and Trans-Port Costs As A Mixed İnteger Programming Problem in Optimization of Land Consolidation. Comput. Electron. Agric. 140, 113-122.

Hung NV 2017. Impacts of Land Consolidation Policy on Agricultural Production in Red River Delta, Vietnam. Park Chung Hee School of Policy and Saemaul of Yeungnam University. Master of Public Policy Thesis.

Hunt D 1983. Farm Power and Machinery Management. Iowa State University Press. 352 Pages.

Kepner RA, Bainer R, Barger EL 1980. Principles of Farm Machinery. AVI, Rub.Cop., Inc, Westpark, Co, USA.

Kumbasaroğlu H, Dağdemir V 2007. Erzurum Merkez İlçede Tarım Arazilerinde Parçalılık Durumuna Göre Tarım İşletmelerinin Ekonomik Analizi. Atatürk Üniversitesi Ziraat Fakültesi Dergisi, 38 (1): 49-58.

Kuşlu Y, Ertem E 2019. Erzurum İli Beypınarı Mahallesi Arazi Toplulaştırma Projesinin Yol Ağı Yeterliliği Açısından Değerlendirilmesi. Atatürk Üniversitesi Ziraat Fakültesi Dergisi, 50 (3): 274281.

Kuzu H, Arslan F, Değirmenci H 2018. Arazi Toplulaştırma Projelerinde Yol Uzunluklarının Analizi: Şanlıurfa Türkeli Köyü Örneği. SDÜ Ziraat Fakültesi Dergisi (Özel say1), 19-25.

Küsek G 2014. Arazi Toplulaştırmasının Arazi Parçalılığı ve İşletme Ölçeğine Etkileri: KonyaEreğli-Kuskuncuk Köyü Örneği. Çukurova Üniversitesi Ziraat Fakültesi Dergisi, 29 (2): 15-28.

Newbold P 1995. Statistics for Business and Economics. Prentice-Hall International, New Jersey, p: 867.

Oğuz C, Bayramoğlu Z 2004. Konya İli Çumra İlçesinde Arazi Toplulaştırması Sonrası Farklı Parsel Genişliklerinin Birim Maliyetler Üzerine Etkisi; Küçükköy Örneği. Selçuk Üniversitesi Ziraat Fakültesi Dergisi, 18(34): 70-75.

Platonova D, Setkovska L, Jankava A 2011. Assessment Principles of Land Fragmentation. Baltic Surveying'11, 117-124. 
Polat HE, Manavbaşı ID 2012. Arazi Toplulaştırmasının Kırsal Alanda Yakıt Tüketimi ve Karbondioksit Salınımına Etkisinin Belirlenmesi. Tarım Bilimleri Dergisi, 18, 157-165.

Sabancı A, Başçetinçelik A, Özgüven F, Öztürk HH, Say SM 2010. Tarım Makinaları 1. Nobel Yayınevi, Adana, 193s.
Say SM 2001. Biçerdöverle Hasatta Biçerdöver Çalışma Güvenirliliğinin Belirlenmesi ve Park Planlaması Üzerinde Bir Araştırma. Çukurova Üniversitesi Fen Bilimleri Enstitüsü. Doktora tezi. $157 \mathrm{~s}$.

Yağanoğlu AV, Okuroğlu M, Hanay A 2000. Arazi Toplulaştırması. Atatürk Üniversitesi Ziraat Fakültesi Ders Yayınları No:159. Erzurum. 169s. 